\title{
O ATRASO COMO PECHA DO CAMPESINATO E A PRODUTIVIDADE COMO MEDIDA DE DESENVOLVIMENTO RURAL
}

\author{
Luciana Ramos Jordão ${ }^{1}$ \\ Thiago Henrique Costa e Silva²
}

\begin{abstract}
RESUMO: O trabalho discute o conceito de desenvolvimento rural, a partir de uma perspectiva socioambiental, encontrada na resiliência do campesinato e sua relevância no cenário político, social, e econômico brasileiro contemporâneo, guiando-se pelo método materialista histórico dialético. Por conseguinte, avalia-se a situação de atraso imputada ao campesinato em contraposição ao termo agricultura familiar. Debate-se, ainda, o conceito de desenvolvimento sob a ótica da modernização conservadora e da produtividade em detrimento de outras questões. Questiona-se as políticas públicas para o campo e o distanciamento das práticas plurais e do conceito de soberania alimentar, concluindo-se pela importância dos movimentos camponeses em suas (re)construções.
\end{abstract}

PALAVRAS-CHAVE: Desenvolvimento rural. Campesinato. Agricultura familiar. Pluralismo.

\section{THE LATE AS A DAMAGE TO CAMPESINATE AND PRODUCTIVITY AS A RURAL DEVELOPMENT MEASURE}

\begin{abstract}
This paper discusses the concept of rural development from a socioenvironmental perspective found in the resilience of the peasantry and its relevance in the contemporary Brazilian political, social, and economic scenario, guided by the dialectical historical materialist method. Therefore, the situation of delay attributed to the peasantry in contrast to the term family agriculture is evaluated. It also discusses the concept of development from the standpoint of conservative modernization and productivity at the expense of other issues. We question the public policies for the countryside and the distance from the plural practices and the concept of food sovereignty, concluding on the importance of the peasant movements in their (re)constructions.
\end{abstract}

KEYWORDS: Rural development. Peasantry. Family farming. Pluralism.

\footnotetext{
1 Advogada. Professora de Direito Agrário e Ambiental do Centro Universitário Alves Faria (UNIALFA). Doutoranda em Agronegócio pela Universidade Federal de Goiás (PPAGRO). Mestre em Direito Agrário pela Universidade Federal de Goiás (PPGDA). E-mail: lr.jordao@me.com.

2 Perito criminal. Professor de Direito Constitucional do Centro Universitário Alves Faria (UNIALFA). Doutorando em Agronegócio pela Universidade Federal de Goiás (PPAGRO). Mestre em Direito Agrário pela Universidade Federal de Goiás (PPGDA). E-mail: thiagocostasilva.jur@gmail.com.
} 


\section{INTRODUÇÃO}

O trabalho visa discutir a noção de desenvolvimento rural tendo em vista a existência do campesinato e sua relevância no cenário social, econômico e ambiental brasileiro contemporâneo. Para tanto, será avaliado o peso do fator produtividade na compreensão de desenvolvimento, levando em consideração a perspectiva de Amartya Sen.

A partir da segunda metade do século XX, com a difusão das tecnologias propaladas pela revolução verde, os integrantes do setor agrícola buscaram se desviar da pecha do campesinato, comumente aliada à perspectiva de atraso, para destacar as possibilidades de crescimento econômico decorrente da adoção de maquinários que facilitassem a produção de commodities. Aliando-se às perspectivas de ganhos financeiros, a discussão, orientada pelos princípios malthusianos, acerca do aumento da produção de alimentos que acompanhasse o incremento populacional orientou as discussões para que os resultados do campo pudessem ser “otimizados”. Assim, o ideal de produtividade corresponderia necessariamente à maior quantidade de produto por hectare plantado.

Na segunda década do século XXI, os excelentes números de produtividade de gêneros como soja, cana-de-açúcar, milho e carne bovina são frequentemente vinculados ao sucesso de técnicas da revolução verde que caracterizam o denominado agronegócio, identificado como sustentáculo econômico em tempos de crise. Ao mesmo tempo, a agricultura de base tradicional, familiar e camponesa, contrariando expectativas que previam sua diferenciação, se mantém como fator relevante, compondo cadeias dos produtos destinados ao comércio internacional, mas especialmente fornecendo uma diversidade de gêneros ao mercado interno.

Ainda assim, dificilmente se reconhece o campesinato dentro de uma estratégia de desenvolvimento rural. Ao contrário, o camponês recebe o estigma de pessoa atrasada, que se recusa a agregar os benefícios que a modernidade lhe trouxe, com um modo de vida obsoleto, que, caso não se adapte, caminha para a inexistência. Ainda assim, a resiliência do camponês é visível na sua capacidade de se reinventar diante das dificuldades e continuar valorizando as suas raízes, de modo que à sua luta por terras, agregam-se outras como a proteção da biodiversidade, a segurança alimentar, a produção de orgânicos, a defesa das sementes crioulas, ou mesmo a manutenção da cultura. 
Por esse motivo, é objetivo deste trabalho estabelecer considerações a respeito do conceito de desenvolvimento rural, de modo que se possa agregar os aspectos sociais, ambientais e culturais, em lugar de limitar a avaliação de sucesso da agricultura à perspectiva econômica. Não sendo possível realizar pesquisa dissociada do contexto social, político e econômico que envolve a questão, pautar-se-á, portanto, no materialismo histórico dialético como método na busca pela construção da realidade a partir dos eventos que ocorreram no Brasil após a segunda metade do século XX.

Por óbvio, não há qualquer pretensão de encerrar o debate, fornecendo conceito definitivo de desenvolvimento rural. Todavia, acredita-se na importância de discutir o assunto a fim de que se passe a traçar políticas públicas que sirvam a conduzir a sociedade dentro de seus valores, respeitando seus modos de vida e a pluralidade de sujeitos que formam o campo brasileiro.

\section{O CAMPESINATO E A PECHA DO ATRASO}

O conceito de campesinato, ao longo dos últimos cinquenta anos, passou a dividir seu espaço com outras duas definições que se aplicam ao campo brasileiro: a agricultura familiar e o agronegócio. Nessa nova subdivisão do campo, enquanto o campesinato remete às formas atrasadas de agricultura que insistem em não se integrar aos mercados, refutando as possibilidades de crescimento econômico que a produção em larga escala proporcionaria, a agricultura familiar representa a atividade moderna e capaz de impulsionar o desenvolvimento das famílias rurais. Por sua vez, o agronegócio englobaria todas as atividades econômicas sistematicamente organizadas nas cadeias de produção agroindustrial (WANDERLEY, 2014).

Em 1964, o Estatuto da Terra estabeleceu que a propriedade rural familiar era aquela trabalhada pela família que poderia eventualmente utilizar mão-de-obra de terceiros. A agricultura desenvolvida nestes espaços se associa à noção de algo pequeno, de caráter não capitalista, bastante à subsistência, consumindo toda a força de trabalho.

Art. $4^{\circ}$ - Para os efeitos desta Lei, definem-se:

II - "Propriedade Familiar”, o imóvel rural que, direta e pessoalmente explorado pelo agricultor e sua família, lhes absorva toda a força de trabalho, garantindolhes a subsistência e o progresso social e econômico, com área máxima fixada para cada região e tipo de exploração, e eventualmente trabalho com a ajuda de terceiros (BRASIL, 1964). 
A área da propriedade familiar corresponde a, no mínimo, um módulo rural. Para que se receba a classificação de agricultor familiar é necessário que a renda provenha predominantemente das atividades do empreendimento de área inferior a quatro módulos fiscais (BRASIL, 2006). Áreas inferiores ao módulo rural, que, por sua extensão são incapazes de atender à sobrevivência básica de uma família, são classificadas como minifúndios (BRASIL, 1964). Aos minifúndios, por serem insuficientes ao cumprimento da função social da propriedade, devem ser aplicadas políticas públicas visando sua extinção (MARQUES, 2015).

Por estes conceitos, percebe-se a não consideração das diversas especificidades dos grupos heterogêneos que compõem o campo brasileiro. Lavradores, ribeirinhos, assentados da reforma agrária, agricultores tradicionais, quilombolas, indígenas, aquicultores, silvicultores passaram a ser designados simplesmente como agricultores familiares para fins de inserção em políticas públicas que não contemplam a pluralidade de suas necessidades, mas, ao contrário, visava facilitar o projeto de modernização do campo, tendo o papel de homogeneizar pelo parâmetro produtivista (NEVES, 2007).

A escolha pelo termo "agricultura familiar” foi efetivada nos anos 1990 a partir da organização do Programa Nacional de Fortalecimento da Agricultura Familiar (PRONAF), com forte influência do Family Farming europeu (CARNEIRO, 1997), servindo como base para a desvinculação da carga política e ideológica, reveladora de conflitos, que o termo campesinato carregava, especialmente vinculada à luta pela reforma agrária empreendida pelas ligas camponesas (WANDERLEY, 1996; RAMOS FILHO, 2008).

O abandono do conteúdo político do conceito conferiu destaque ao critério meramente econômico na utilização da terminologia "agricultura familiar”, utilizada para justificar e esclarecer o funcionamento das famílias rurais que se organizam de modo peculiar em torno da família e dos relacionamentos construídos com seus vizinhos (WANDERLEY, 2014), mas que doravante teriam que integrar-se a lógica mercadológica de aumento de produção, seguida de diminuição de preço, que culminaria em possibilidade de ser competitivo (CARNEIRO, 1997).

Seguindo essa lógica dicotômica entre o moderno e o atrasado, Ricardo Abramovay (2007), ao discutir a diferenciação existente entre a agricultura familiar e o campesinato, alinha o primeiro conceito a estabelecimentos modernos que passam por problemas inerentes a essa modernidade e à mecanização (superprodução, dificuldades de armazenamento, danos ambientais decorrentes de uso indiscriminado de insumos, endividamento em razão de 
financiamentos para modernização), enquanto o campesinato configuraria um conceito meramente histórico.

Ao contrário do atraso identificado no campesinato, a natureza das dificuldades dessa nova categoria evidenciaria que o caráter familiar não constitui um peso indesejado a ser eliminado em nome do desenvolvimento, pois, ao contrário, deveria ser aproveitado, sendo que a saída para o sucesso agricultura familiar seria a realização de investimentos que a integrassem no negócio agropecuário brasileiro, a exemplo do que ocorreria com os agricultores e pecuaristas europeus (ABRAMOVAY, 2007).

Mesmo nesse viés econômico, que critica a viabilidade de uma propriedade familiar ou camponesa e da necessidade de apoio estatal, é preciso destacar que, em um contrassenso, a análise da viabilidade do agronegócio não leva em conta os esforços estatais necessários a sustentar a atividade da agricultura patronal por meio de políticas públicas de crédito subsidiado. A modernização da agricultura se estabelece sob o braço de proteção do Estado que, complacentemente, desconsidera os números das dívidas roladas para realizar os investimentos e o custeio da produção e aponta como resultados números índices que não refletem a dependência de insumos internacionais e a vulnerabilidade do setor agrícola (MENDONÇA, 2015).

Uma análise comparativa dos censos agropecuários do Instituto Brasileiro de Geografia e Estatística (IBGE), de 1940 a 1970, mostra que a produção triplicou no Brasil. Ao mesmo tempo, houve um aumento de vinte vezes no preço dos adubos, de oito vezes no custo de agrotóxicos, de trinta vezes nas sementes, mudas e rações, e de quatro vezes em animais, máquinas e veículos. O custo de produção passou de 7,25\% para 19,88\% em relação ao preço da produção agropecuária. Em 1976, o setor acumulava uma dívida de 13 bilhões de dólares. Esses dados indicam transferência de renda do setor agrícola para o industrial, através da dependência de máquinas e insumos químicos no processo de produção, assim como no momento da comercialização, ambos controlados por empresas transnacionais (MENDONÇA, 2015, p. 40).

Para além da questão econômica, contemporaneamente, entre os integrantes de Movimentos Sociais de luta pela terra é possível verificar a retomada do termo campesinato para conferir destaque às críticas quanto à modernização conservadora e às questões sociais e ambientais (WANDERLEY, 2014).

O desafio do próximo período para os movimentos sociais camponeses é colocar a disputa em outro patamar e cobrar políticas estratégicas de Estado que visem superar a miséria que ainda desgraça amplos setores camponeses, garantir a preservação dinâmica da forma de vida camponesa com suas comunidades e sua 
cultura, e proporcionar o desenvolvimento do campesinato como o principal sujeito social da produção de alimentos com preservação ambiental (LEAL; GÖRGEN, 2015, p. 89).

Ainda assim, as políticas públicas se estabelecem no sentido de prestigiar os agricultores que atendem aos desígnios do mercado, enquadrando-se no ideal de agricultor familiar moderno, ou seja, apto a se desenvolver economicamente dentro agronegócio. A diferenciação entre o campesinato e a agricultura familiar tem como consequência a desconsideração do trabalhador camponês quando da elaboração de políticas públicas. Afinal, atender ao campesinato, posto como algo ultrapassado, significaria investir em setor falido com do qual não se pode obter desenvolvimento (DUVAL; FERRANTE; BERGAMASCO, 2015).

Para que seja possível discutir o conceito de agricultura familiar, conforme Carneiro (2008), é preciso avaliar não apenas as relações entre os indivíduos, mas também o emaranhado de valores que integram as relações familiares de modo geral. A família, por si, não é um corpo homogêneo de interesses e posicionamentos. Por vezes, questões vinculadas ao gênero, à diferença entre gerações, posição social direcionam as discussões e as escolhas econômicas das famílias independentemente de se tratarem de grupos urbanos ou rurais.

A compreensão das dinâmicas de relacionamento dentro das famílias permite o entendimento a respeito da forma como se processa a sucessão no campo, o êxodo rural feminino, o êxodo de jovens e a realização de atividades não agrícolas por integrantes de famílias rurais (CARNEIRO, 2008).

Entre as famílias, o trabalho é coletivo e dividido entre os membros. Igualmente, a renda pertence à família de modo indiviso, mas a administração, é dada ao patriarca, que gerencia o resultado do trabalho. Assim, as demandas dos jovens se tornam reféns do arbítrio adultos. E as necessidades que lhes são próprias em virtude da idade e da cobrança socialmente imposta esbarram na falta de acesso a dinheiro, propriamente dito, gerando conflitos na família. A renda indivisa impulsiona a busca de trabalho fora da família para encontrar autonomia no campo (CARNEIRO, 2008).

A família não constitui simplesmente unidade de produção, mas unidade social com características peculiares que podem ser identificadas independentemente da atividade econômica desenvolvida tradicionalmente por seus membros. Mesmo a expansão das atividades não agrícolas pode ser compreendida como resultado da necessidade de mulheres e jovens, por exemplo, de terem acesso à renda própria que não esteja sujeita à administração do patriarca da família. Casos há, todavia, em que a pluriatividade auxilia na manutenção das atividades 
agrícolas, por exemplo, quando rendas de atividades não agrícolas são destinadas à realização de investimentos no imóvel rural (CARNEIRO, 2008).

A pluriatividade e a realização do trabalho não agrícola não desnaturam o campesinato. Ao contrário, o fato de os camponeses buscarem outras fontes de renda para sustentar as necessidades dos mais jovens ou realizar investimentos dentro das propriedades decorre do esforço dessas populações para manterem seu modo de vida e superar as vicissitudes que se lhes apresentam.

Se o trabalho fora do sítio familiar se impõe como uma necessidade para complementar a renda ou para encaminhar profissionalmente os filhos, ele não é percebido em contradição com as atividades agrícolas, porém, de modo articulado a essas, sob a forma de um sistema de atividades familiar, sobre o que muito ainda há a compreender. Assim, como para afirmar sua identidade de agricultores, eles têm uma experiência acumulada de estratégias e de práticas sociais, inclusive no campo produtivo, que revelam sua capacidade de sobreviver, enfrentando situações de grande precariedade, a respeito do que, no Brasil, já se dispõe de uma vasta bibliografia (WANDERLEY, 2015, p. 40).

Maria de Nazareth Baudel Wanderley (2014) entende que a opção pelo conceito de agricultura familiar não reflete a representação histórica e política aplicável ao campesinato, retirando-lhe a caracterização de modo de vida pautada pela organização do trabalho de modo cooperativo. O modo de vida camponês abrange não apenas os integrantes das famílias, mas implica forma própria de produzir e de se relacionar com as pessoas, em um sistema que vai além do contratual, fundando na confiança dos vínculos criados ao longo da vida (MENDRAS, 1978). A desconsideração do campesinato enquanto forma de viver implica ignorar a existência e a reprodução social de cultura que insiste em se estabelecer mesmo sobre a pecha de atraso que a ela se associa.

O campesinato é compreendido como modo de produção e de vida, com particularidades culturais marcadamente regionais, mas com uma base de interesses sociais, econômicos e políticos que o unifica, colocando-o como um sujeito político na história nacional em confronto com os interesses das classes dominantes e o pacto de poder manifesto nas políticas de Estado. Nesta concepção a resistência e a luta jogam papel fundamental na reprodução e ampliação do campesinato. O campesinato é um sujeito social e político (LEAL; GÖRGEN, 2015, p. 90-91).

O estabelecimento da carga de atraso que recai sobre o conceito de campesinato cria obstáculos tangentes à elaboração e implementação de políticas públicas suficientes a atender essas populações. Se a agricultura familiar é objetivo, se a modernização e a inserção 
no mercado de produção de commodities são o caminho para o desenvolvimento, não há justificativa que sustente políticas públicas de amparo ao campesinato. E, diante da escolha pela agricultura familiar, identifica-se parcela do campo que se mantém alijada do aparato estatal, que não só se olvida das necessidades concretas desta população como atua para sedimentar o debate a respeito de sua dispensabilidade. Pois, “[...] as políticas é que devem responder às necessidades concretas do seu público alvo e não o contrário [...]” (WANDERLEY, 2015, p. 42).

Dados a respeito do PRONAF, por exemplo, estabelecem que, apesar do aumento dos valores negociados, o número de produtores beneficiados pelo Programa não demonstrou elevação significativa. Isso indica que, todo ano, as mesmas pessoas têm acesso ao financiamento. O programa não obtém a capilaridade desejada, o que se verifica pelo fato de ser registrada diminuição na quantidade de pessoas atendidas a despeito do aumento no valor investido. Dentre os agricultores atendidos, 47\% se encontram na região Sul do país e os contratos prestigiam as atividades consolidadas em lugar de se aplicarem a outras que possam se adequar às necessidades de camponeses. Muitos agricultores não conseguem vencer a burocracia e a tendência de escolha dos agentes financeiros para implantar seus projetos e diversificar a produção (AQUINO e SCHNEIDER, 2010; CORCIOLI e CAMARGO, 2016).

O PRONAF é uma política importante, mas sua elaboração atende ao conceito de agricultura familiar. O campesinato e seus valores ambientais, culturais e socioeconômicos não são considerados na sua formulação ou implementação.

Nesse sentido, os Movimentos Sociais destacam a importância da criação do PRONAF na manutenção do trabalhador camponês, auxiliando em sua permanência no campo e na melhoria das condições de vida e de produção dos trabalhadores. Reconhecem, no entanto, que o PRONAF não acompanhou os desafios que o cenário de mudanças climáticas e preocupações com alimentação saudável e impõem à sociedade e aos trabalhadores camponeses (LEAL; GÖRGEN, 2015).

Uma das vertentes sobre a qual se estrutura a pecha do atraso do campesinato reside nos números de produtividade por área ocupada e no temor de que formas de agricultura que não se apoiem no uso de insumos, máquinas agrícolas e técnicas da revolução verde sejam insuficientes para atender à demanda por alimentos e produção de commodities agrícolas (BUAINAIN et al., 2013). A despeito disso, agricultores camponeses se atentam à crescente demanda por alimentos ecológicos, produzidos localmente, em consonância com a realidade cultural e climáticas dos locais onde habitam. 
No Brasil, o papel da produção agrícola local e da agricultura de subsistência é comumente subestimado ou mesmo ignorado nos dados econômicos oficiais, apesar de garantir o sustento da maioria da população. Há na atualidade um movimento crescente de demanda por alimentos ecológicos e produzidos localmente, na Europa e nos Estados Unidos. Um dos lemas desse movimento é "quilômetro zero", que defende a agricultura local. Enquanto isso, o Estado brasileiro compromete enormes montantes de recursos públicos para financiar a produção de commodities agrícolas, que constituem uma pauta de exportação cada vez mais reduzida. Tal política reforça a violência contra povos indígenas, camponeses e quilombolas e compromete a possibilidade da construção da soberania alimentar e do pleno direito à alimentação (MENDONÇA, 2015, p. 42).

A agricultura camponesa desempenha importante papel no fornecimento de alimentação para populações urbanas e rurais, sendo responsável por 36,11\% da produção de alimentos, especialmente para atender o mercado interno (GUANZAROLI e DI SABBATO, 2012). Os agricultores familiares seriam

responsáveis por 70\% do feijão, 87\% da mandioca, 38\% do café, 46\% do milho e 34\% do arroz. Na pecuária, respondem por 59\% dos suínos, 50\% das aves, 30\% da carne bovina e 58\% do leite. A desigualdade também está presente nos tipos de produção. Por exemplo, $1,57 \%$ dos estabelecimentos produtores de milho respondem por $68,31 \%$ da produção, e 26,7\% do leite vêm de 80,41\% dos estabelecimentos produtores, ou seja, 19,59\% produtores fazem 73,3\% do leite (FERNANDES, 2013, p. 204).

Dessa forma, os Movimentos Sociais passaram a adotar a concepção de soberania alimentar, apresentada durante a Primeira Cúpula Mundial da Alimentação, realizada pela FAO em 1996, como alternativa que compreende não apenas as necessidades relacionadas ao abastecimento, mas também as questões sociais pertinentes (VÍA CAMPESINA, 2001; MARTÍNEZ-TORRES; ROSSET, 2010). A agricultura de base familiar e camponesa passa, então, a englobar um projeto político de desenvolvimento, mesmo que não seja o hegemonicamente pensado ou o que norteia as políticas agrárias.

Apesar da necessidade de reconhecer a "agricultura familiar" como um instrumento jurídico e político, ainda que com inúmeros problemas, de reconhecimento da existência de diversos segmentos sociais do campo (AQUINO e SCHNEIDER, 2011), o termo oculta o campesinato e a sua resiliência, que configuram uma verdadeira crítica ao projeto de 
modernização, evidenciada por seus projetos agroecológicos, por suas críticas ao sistema monocultor de exportação, ou ainda por impor a necessidade de se repensar o modelo de desenvolvimento rural brasileiro (WANDERLEY, 2014; FERNANDES, 2013; NEVES, 2007).

\section{DESENVOLVIMENTO RURAL E PLURALISMO: O CAMPESINATO COMO MEIO DE (RE)CONSTRUÇÃO DE POLÍTICAS PÚBLICAS}

Amartya Sen (2010) entende o desenvolvimento como um processo decorrente da expansão das liberdades desfrutadas pelas pessoas de modo real. Para obter situação de desenvolvimento, seria necessário, portanto, remover causas de privação de liberdade como a pobreza, a fome, a tirania, a ausência de serviços públicos básicos, a intolerância, entre outros.

A riqueza é vista por Amartya Sen (2010) como um dos fatores a serem considerados na avaliação de desenvolvimento porque o poder econômico permite acesso a itens como educação, saúde e alimentação. Mas a simples consideração da pobreza como elemento definidor do desenvolvimento redunda em generalizações que impedem a compreensão de outros fatores que envolvem as políticas públicas.

Ainda assim, a elevação da renda de comunidades rurais, que possibilita também a elevação do acesso à educação e saúde, depende do aproveitamento de aspectos vinculados ao patrimônio cultural e natural em suas peculiaridades. Por sua vez, José Eli da Veiga (2002) destaca que o desenvolvimento de áreas rurais não tem como pressuposto sua conversão em área urbana ou mesmo não-rural. Citando o exemplo do campo dos Estados Unidos, o autor observa que as áreas rurais de países avançados que permanecem em estado de subdesenvolvimento são aquelas que não conseguiram explorar potencial turístico, ambiental ou servir como destino para aqueles que buscam vida saudável em local distante dos centros urbanos.

Quanto maior o acesso das pessoas à cultura, educação e cidadania, melhores resultados se obtêm no tangente ao desenvolvimento e à qualidade de vida de modo global. Isso se verifica também no fato de países democráticos padecerem menos com fome e desnutrição coletiva em comparação com países que passam por regimes ditatoriais (SEN, 2010).

É certo que a produção de alimentos é (ou já foi?) um fator importante para o combate à fome, contudo existem outros problemas que precisam ser enfrentados. Mesmo o aumento ou a redução de índices de produtividade dos países não podem ser diretamente 
associados à existência ou não de fomes coletivas. Isso se dá porque há casos de países que observaram queda em sua produção, mas que não passam por problemas de abastecimento em razão da obtenção de alimentos de outras localidades.

A tendência a pensar no aumento das culturas como a única maneira de resolver um problema de insuficiência de alimentos é forte e tentadora, e às vezes realmente tem uma certa base racional. Mas o quadro é mais complexo e se relaciona a oportunidades econômicas alternativas e a possibilidades de comércio internacional. No que concerne à falta de crescimento, característica principal dos problemas da África subsaariana não é especificamente a ausência de crescimento na produção de gêneros alimentícios, mas a ausência geral de crescimento econômico (da qual o problema da produção de alimentos é apenas uma parte). A necessidade de uma estrutura de produção mais diversificada é muito acentuada na África subsaariana, dadas as incertezas climáticas de um lado e a possibilidade de expansão em outras áreas de atividade produtiva, de outro (SEN, 2010, p. 231).

A produção de alimentos e a busca por aumento de índices de produtividade não possui, por si, a aptidão de conduzir uma população ao status de desenvolvimento. Ocorre que, a aposta única na expansão da agricultura é estratégia que desconsidera os benefícios da diversificação das atividades econômicas no que tange ao acesso aos recursos e liberdades. $\mathrm{O}$ apego a uma fonte de renda e crescimento gera dependência e vulnerabilidade que expõem a população a situações de miserabilidade em casos de crises no setor eleito como prioridade. “A tão preconizada estratégia da concentração exclusiva na expansão da agricultura especificamente nas culturas alimentares - equivale a apostar tudo em um só cavalo, e os riscos dessa política podem ser imensos” (SEN, 2010, p. 231).

Interessante avaliar que, verificando os índices de produção de alimentos em cada um dos continentes, Sen (2010) constatou haver aumento dos números de produtividade per capita entre as décadas de 1970 e 1990 mesmo num cenário de queda dos preços. Igualmente, a Organização das Nações Unidas para Agricultura (FAO), registrou o aumento na produção de alimentos per capita em quase todos os continentes, com exceção da África. Ainda assim, a existência de quantidade de alimentos suficientes para a população não implica sua disponibilidade (FAO, 2015).

A liberdade de acesso aos alimentos é determinada por outros fatores que não se associam à quantidade de alimentos produzidos de modo direto. Entre estes fatores, consideram-se os preços dos alimentos, a possibilidade de aquisição decorrente dos ganhos individuais, acesso a políticas públicas de amparo social, dentre outras. Ainda, outras variáveis sociais, como gênero, posição social, ou estruturais, como disponibilidade física, infraestrutura e logística, são alguns exemplos da complexidade do tema (FAO, 2015). 
Amartya Sen (2010) associa o aumento de produtividade por hectare ao crescimento da produção de modo geral, considerando que, entre 1970 e 1990, somente 6\% do aumento dos resultados de cereais se vincula à expansão da área cultivada. A mesma tendência foi verificada pela FAO (2015), ao registrar o aumento da produção de milho na América Latina e África subsaariana como resultado desvinculado da expansão das áreas de cultivo.

Na verdade, pode ser imensamente contraproducente a tendência a concentrar-se apenas na produção de alimentos, desconsiderando o intitulamento aos alimentos. Os responsáveis pelas políticas podem equivocar-se se forem isolados do quadro real de fome - e mesmo de ameaças de fomes coletivas - por situações favoráveis da produção de alimentos (SEN, 2010, p. 270).

Em outros termos, o produtivismo, como forma de acabar com a fome, traz consigo uma outra variável, a busca pelo crescimento econômico, sem uma preocupação com um desenvolvimento sustentável, agregando questões como o uso da terra, os diferentes modos de vida, a proteção aos patrimônios históricos e religiosos, a preservação genética, dentre tantos outros elementos (VEIGA, 2010).

Associada a essas preocupações socioambientais, a noção de desenvolvimento rural e sua identificação com a possibilidade de acesso a direitos humanos básicos conduzem à valorização da pluralidade democrática e da diversidade cultural por meio da identificação dos potenciais locais de vida humana digna. Consoante Antonio Carlos Wolkmer (2006, p. 114) “[...] impõe-se repensar politicamente o poder de ação da comunidade, o retorno dos agentes históricos, o aparecimento inédito de direitos relacionados às minorias e à produção alternativa de jurisdição, com base no viés interpretativo da pluralidade de fontes”.

O estabelecimento de formas de diálogo intercultural a partir da legitimação cultural de comunidades tradicionais na América Latina indicam a possibilidade de construção de cultura pluralista apta a se comprometer com a alteridade, autonomia, identidade coletiva, respeito aos valores e acesso a direitos (WOLKMER, 2006).

Diante do declínio das práticas tradicionais de representação política, da escassa eficácia das estruturas judiciais e estatais em responder à pluralidade de demandas e conflitos, do crescente aumento de bolsões de miséria e das novas relações colonizadoras de países ricos com nações em desenvolvimento, abre-se a discussão para a consciente busca de alternativas capazes de desencadear diretrizes, práticas e regulações voltadas para o reconhecimento à diferença (singular e coletiva) de uma vida humana com maior identidade, autonomia e dignidade (WOLKMER, 2006). 
Compreender o campesinato, como grupo heterogêneo, em que se integram grupos marcados pela diversidade, alteridade, e peculiaridades culturais, é importante que as políticas públicas ou mesmo a estratégia de desenvolvimento rural do Brasil considerem as suas necessidades, modos de vida, e ensinamentos, promovendo uma verdadeira (re)construção de conceitos partindo do nacional e do local.

Assim, a análise dos sujeitos sociais e da prática de respeito aos direitos humanos garante o direito de existência e reconhecimento das diferenças, de modo a considerar as diferentes contribuições da sociedade para a elaboração de políticas públicas atentas à diversidade (WOLKMER, 2006).

É nesse sentido que a Via Campesina (2001) relaciona os problemas da fome e desnutrição às políticas agrícolas e comerciais impostas por países desenvolvidos e suas corporações ansiosas por manter a hegemonia política, cultural, militar e econômica que ostentam. Por esse motivo, os Movimentos Sociais propõem a análise do campo sob a perspectiva da soberania alimentar, não mais da segurança, a fim de estabelecer políticas públicas que atendam ao desenvolvimento local por meio de cultura de gêneros agrícolas adaptados a cada região e que integrem a cultura alimentar das populações.

De fato, a participação do Estado na elaboração de políticas públicas e o direcionamento das estratégias de desenvolvimento rural passam pela delimitação dos objetivos a que se pretende. E a compreensão desses objetivos se verifica, entre outros fatores, pela análise dos princípios que orientam a atuação estatal. O Estado europeu se estrutura em princípios de liberdades individuais, na propriedade privada e na divisão de poderes. Os países latino-americanos se sustentam por uma modernização conservadora encabeçada pelo Estado e realizada em ambiente de capitalismo tardio. As oligarquias escravocratas adotaram o modelos europeus como seus ideais, fato totalmente alheio às peculiaridades da população (WOLKMER; FAGUNDES, 2013).

Num cenário de administração centralizadora e dissociada do reconhecimento da pluralidade existente na maior parcela da sociedade, o Estado brasileiro se estabeleceu sem que a ele se atrelasse uma identidade nacional. A elite agrária brasileira e as rupturas políticas que permearam o século XX se prestaram, na verdade, a perpetuar o poder daqueles que determinavam os caminhos do Estado. Para que a sociedade se mantivesse unificada sobre um Estado que não a refletia, utilizou-se na América Latina e no Brasil, em mais de uma oportunidade, o peso das ditaduras, a força coercitiva da lei e a deslegitimação consistente de 
movimentos sociais populares (WOLKMER; FAGUNDES, 2013), mas são nesses movimentos e nessa pluralidade que as políticas públicas atuais devem ser (re)construídas.

Nesse sentido, o campesinato é resiliente e concentra nos modos de vida e na relação homem-natureza uma crítica ao modelo produtivo hegemônico. A modernidade camponesa está no que convencionaram chamar de atraso: pensar o homem incluído na natureza e não o oposto, para além da produtividade e do mero crescimento econômico. Logo, pensar “modernamente" o desenvolvimento rural deve ser fruto de uma agenda plural, em que os camponeses e seus saberes sejam levados em conta.

\section{CONSIDERAÇÕES FINAIS}

O debate acerca da modernidade e da necessidade de movimentação do aparato estatal para sustentação do agronegócio encontra justificativa nos índices, anualmente divulgados, que apontam para os benefícios econômicos do setor. Enquanto isso, propagandeiase a conversão do atrasado campesinato na agricultura familiar, como se sua extinção significasse um passo adiante no caminho do desenvolvimento.

Neste ponto, o desenvolvimento costuma ser relacionado ao cumprimento de metas puramente econômicas que chegam a ignorar a finalidade pela qual o ser humano trabalha a terra. Ainda, o direito humano à alimentação adequada, enquanto elemento integrante do debate a respeito da produtividade do campo, é deixado em segundo plano, todavia, de nada adianta que haja números expressivos de produtividade, se parte da população morre de fome. De nada servem os imensos campos de soja se a população local não se serve desse alimento e se falta na mesa alimentos tradicionalmente consumidos e que garantam uma segurança nutricional.

Dessa forma, pensar o conceito de desenvolvimento a partir da perspectiva da soberania alimentar e das discussões empreendidas pelos movimentos sociais camponeses constitui um caminho capaz de abrigar as necessidades dos verdadeiros destinatários das políticas públicas.

O estabelecimento das metas a serem atingidas não podem continuar a se espelhar no padrão europeu de desenvolvimento sem avaliar a pluralidade de atividades que permeiam o campo brasileiro, ignorando suas necessidades e a diversidade existente dentro da população.

Em sociedades camponesas latino-americanas, o modelo positivista de base individual e monocultural não basta para conduzir à elaboração de conceito de desenvolvimento 
rural que suporte as peculiaridades locais. Reduzir o campesinato à contingentes produtivos não é suficiente para identificar os potenciais das sociedades e ignorar as possibilidades que se descortinam em razão da alteridade e da diversidade dessas culturas, por certo, há de causar mais prejuízo do que benefício.

Não é possível estabelecer estratégias de desenvolvimento rural sem precisar o que o conceito quer dizer. Se o campo se presta tão somente à produção, nada mais há que analisar além dos números por hectare. Mas, caso os aspectos sociais, ambientais, culturais também tenham relevância para a sua mensuração, é possível concluir que a noção de produtividade por área e o mero crescimento econômico são insuficientes para atender a noção de desenvolvimento.

Nesse sentido, o acesso a direitos humanos, liberdades individuais, direitos sociais e difusos, enquanto critério para avaliação de desenvolvimento, culmina na avaliação de aspectos ligados à cultura das populações rurais e ao direcionamento das políticas públicas para as necessidades que efetivamente existem.

A criação jurídica de uma categoria para facilitar o acesso às políticas públicas não apaga a complexidade social existente na sociedade. O campesinato é realidade inafastável. O camponês existe e resiste em suas tradições, provocando contradições. O camponês persiste e, por sua versatilidade e capacidade de adaptação, demanda soluções para que as ações estatais não aniquilem seu modo de vida e os seus ideais. Há mais do que o viés econômico pode abranger, portanto (re)construir o desenvolvimento rural e as políticas públicas para o campo em uma perspectiva moderna importa em considerar os camponeses e a pluralismo que os norteiam.

\section{REFERÊNCIAS}

ABRAMOVAY, R. Paradigmas do capitalismo agrário em questão. 3. ed. São Paulo: EdUSP, 2007.

AQUINO, J. R.; SCHNEIDER, S. 12 anos da política de crédito do PRONAF no Brasil (19962008): uma reflexão crítica. Revista de extensão e estudos rurais. v. 1, n. 2, p. 309-347, jul.dez. 2011.

BRASIL. Lei $n^{\circ}$ 4.504, de 30 de novembro de 1964. Dispõe sobre o Estatuto da Terra, e dá outras providências. Diário Oficial - República Federativa do Brasil: Poder Executivo, Brasília, DF, 30 nov. 1964.

. Lei $\mathrm{n}^{0}$ 11.326, de 24 de julho de 2006. Estabelece as diretrizes para a formulação da Política Nacional da Agricultura Familiar e Empreendimentos Familiares Rurais. Diário 
Oficial - República Federativa do Brasil: Poder Executivo, Brasília, DF, 25 jul. 2006.

BUAINAIN, A. M. et al. Sete teses sobre o mundo rural brasileiro. Revista de Política Agrícola, v. 22, n. 2, p. 1-25, 2013.

CARNEIRO, M. J. Em que consiste o familiar da agricultura familiar? In: COSTA, L. F. C.; FLEXOR, G.; SANTOS, R. (Org.). Mundo rural brasileiro: ensaiar interdisciplinares. Rio de Janeiro: Mauad X; Seropédica, 2008. p. 255-269.

Política pública e agricultura familiar: uma leitura do PRONAF. Revista Estudos,

Sociedade e Agricultura, abr. 1997.

CORCIOLI, G.; CAMARGO, R. Programa Nacional de Fortalecimento da Agricultura Familiar (PRONAF). In: Agricultura familiar em Goiás: lições para o assessoramento técnico. Goiânia: UFG, 2016. p. 183-252.

DUVAL, H. C.; FERRANTE, V. L. S. B.; BERGAMASCO, S. M. P. P. Sobre o uso da teoria do campesinato na contemporaneidade. Raízes, v. 35, n. 1, p. 62-78, 2015.

FAO. Food and Agriculture Organization. FAO Statistical Pocketbook 2015: world food and agriculture. Roma: FAO, 2015.

FERNANDES, B. M. A reforma agrária que o governo Lula fez e a que pode ser feita. In: SADER, Emir. 10 anos de governos pós-neoliberais no Brasil: Lula e Dilma. São Paulo: Boitempo; Rio de Janeiro: FLACSO Brasil, 2013.

LEAL, M.; GÖRGEN, S. A. Desafios da agricultura camponesa no século XXI. In: Direitos Humanos no Brasil 2006: relatório da rede social de justiça e direitos humanos. São Paulo: Expressão Popular, 2015. p. 87-96.

MARQUES, B. F. Direito agrário brasileiro. 11. ed. São Paulo: Atlas, 2015.

MARTÍNEZ-TORRES, M. E.; ROSSET, P. La Vía Campesina: the birth and evolution of a transnational social movement. Journal of Peasant Studies, Londres, n. 37, p. 149-175, 22 jan. 2010.

MENDONÇA, M. L. A crise permanente do agronegócio. In: Direitos humanos no Brasil: Relatório da Rede Social de Justiça e Direitos Humanos. São Paulo: Expressão Popular, 2015. p. 37-44.

NEVES, D. P. Agricultura familiar: Quantos ancoradouros! In: FERNANDES, Bernardo Mançano; MARQUES, Marta Inez Medeiros; SUZUKI, Julio Cesar (orgs.). Geografia Agrária: Teoria e Poder. - 1.ed. - São Paulo: Expressão Popular, 2007. p. 211-270.

SEN, A. Desenvolvimento como liberdade. São Paulo: Companhia das Letras, 2010.

VEIGA, J. E. A face territorial do desenvolvimento. Interações (Campo Grande), v. 3, n. 5, set. 2002.

VEIGA, J. E. Desenvolvimento sustentável: o desafio do século XXI. Rio de Janeiro: Garamond, 2010.

WANDERLEY, M. N. B. O campesinato brasileiro : uma história de resistência. Revista de 
Economia Social Rural, v. 52, n. 1, p. 25-44, 2014.

. Raízes históricas do campesinato brasileiro. Trabalho apresentado no XX Encontro Anual da ANPOCS. GT 17 - Processos sociais agrários. Caxambu-MG. Out. 1996.

WOLKMER, A. C. Pluralismo jurídico, direitos humanos e interculturalidade. Seqüência: Estudos Jurídicos e Políticos, v. 27, n. 53, p. 113-128, 2006.

WOLKMER, A. C; FAGUNDES, L. M. Para um Novo Paradigma de Estado Plurinacional na América Latina. Novos Estudos Jurídicos, v. 18, n. 2, p. 329-342, 2013.

VIA CAMPESINA. Declaración Final del Foro Mundial sobre Soberanía Alimentaria. Havana, Cuba, 7 set. 2001, p. 4. 